\title{
A ideia da saudade em Teixeira de Pascoaes e Carlos Drummond de Andrade ${ }^{1}$
}

\author{
Andrés José Pociña López \\ Universidad de Extremadura (Cáceres - Espanha)
}

Ó saudade que és das dores a mais linda

Teixeira de Pascoaes, À Ventura

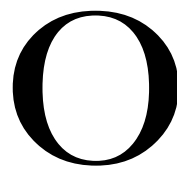

sentimento da saudade é o mais caracterizado e o melhor definido entre aqueles que se podem encontrar no acervo da sensibilidade Galego-Portuguesa - este sentimento, tão Galego como Português, e a partir dá espalhado pelas sete partidas do mundo, pese à sua "originalidade" ou ao seu nome "intraduzivel", não deixa de ser um sentimento absolutamente humano e, portanto, universal. ${ }^{2}$

Dentro do mundo celta em particular, a saudade não parece ser estranha à sensibilidade Celta, lírica e sonhadora, havendo nela estados de alma muito semelhantes, como a "hiraeth" dos Galeses, cuja estreita relação com a saudade já foi posta de manifesto pelo estudioso Galês

${ }^{1}$ Desejamos que fique aqui expresso o nosso sincero agradecimento à professora Carolina Amador, do departamento de Filologia Inglesa da nossa faculdade, bem como à professora Iolanda Ogando, do departamento de Filologia Românica, também da nossa faculdade, sem a ajuda de quem não teríamos podido aceder à informação necessária para enviar este artigo à revista onde aparece agora publicado.

${ }^{2}$ Eduardo Lourenço (LOURENÇO, 1999. p. 114) pergunta-se, de facto, se "não será saudade um nome, entre outros, com que se exprime alguma coisa de mais universal". A ideia (isto é: a saudade como sentimento universal, mas com um nome absolutamente particular em português, o que torna tal sentimento distinto doutros semelhantes noutras culturas) parece-me muitíssimo sugestiva. 
Robert G. Havard. ${ }^{3}$ Para Havard, com efeito, "la saudade/ hiraeth radica en este sentido de haber perdido algo, de estar separado de algo, y abarca el sentido de querer recobrarlo". ${ }^{4}$ Para além disso, constata-se a existência de diversos temas, com uma força emocional especialmente intensa, que em si abrangem a maior parte da atenção do sujeito arrebatado por tal sentimento: esses temas são semelhantes nas sensibilidades GalegoPortuguesa, por um lado, e na Galesa, por outro. ${ }^{5}$ Para o pensador Galego Ramón Piñeiro, ${ }^{6}$ a saudade seria um sentimento típico dos povos do Norte Europeu, deslocado à Galiza e Portugal, decorrendo da particular tendência à introversão e individualidade desses povos, facto este que significaria uma comunidade de sensibilidades entre os povos GalaicoLusófonos e os povos germânicos e célticos do Norte e Noroeste da Europa. Teixeira de Pascoaes, porém, parece ter mais interesse em pôr em relevo as ligações entre o sentimento saudoso e outras formas de emoção, semelhantes, existentes dentro do contexto da Península Ibérica:

O Portugal de Camões, a Galiza de Rosalia, a Catalunha de Maragall são os Reinos da Saudade, como a fidalga Castela é o Reino de D. Quixote. Mas nas alturas azuis da Ibéria, na Ibéria do Infinito, D. Quixote e a Saudade pairam, como dois anjos tutelares da alma peninsular, a mais poética e original que criou a Terra.?

É, porém, a ideia mais estendida e repetida, aquela que nos quer fazer observar a saudade como algo de genuinamente Galego-Português, como que uma particularidade privativa do espírito destes dois povos, e da sua projecção pela Lusofonia em geral, do Brasil até Macau. Mas, para além disto, é-nos necessário reconhecer que ainda não está de tudo esclarecida a verdadeira significação do termo "saudade" - ainda não tem, por assim dizer, uma "definição" de tipo psicológico, que faça compreensível o termo para as pessoas estranhas à cosmovisão tipicamente Lusófona, ou Galaico-Lusófona (se é que tal cosmovisão realmente existe), e menos ainda uma "definição" que a todos, por igual, satisfaça e a todos, por igual, convença.

\footnotetext{
${ }^{3}$ Cf. HAVARD, 1986.

${ }^{4}$ HAVARD, 1986. p. 218.

${ }^{5}$ HAVARD, 1986. p. 218.

${ }^{6}$ PIÑEIRO, 1984. p. 43.

${ }^{7}$ PASCOAES, 1987. p. 166.
} 
Seguindo a Jacinto do Prado Coelho, ${ }^{8}$ parece-nos que a emoção que deu origem à saudade mais não seria do que uma forma, aliás pouco definida, de solidâo: soidade, suidade, que nos Cancioneiros Velhos e no Cancioneiro Geral exprime a dor de uma separação, de uma lonjura que dói, de um afastamento da terra, da mulher ou dos tempos passados que se amam. Tal noção saudosa alcançaria a sua máxima expressão na célebre obra Saudades, de Bernardim Ribeiro, de todos conhecida como $A$ Menina e Moça. ${ }^{9}$ Mas que a ideia particular da saudade - entanto mistura de afetos tristes e doces, entanto palavra intraduzível para outros idiomas - estava já presente na mentalidade Portuguesa da época, é demonstrado pelo facto de tal ambivalência e peculiaridade ter sido posta de relevo pelo rei, e importante escritor, do século XV, D. Duarte, embora tal ideia tenha sido mais aprofundada pelo escritor e pensador Manuel de Melo, segundo põem de manifesto Prado Coelho ${ }^{10}$ ou Eduardo Lourenço. ${ }^{11}$ Em particular, a teorização de D. Duarte, no seu célebre livro, o Leal Conselheiro, ${ }^{12}$ parece-nos especialmente relevante, por ser a primeira exposição de tipo filosófico a tratar de desentranhar os mistérios deste peculiar afeto, pese às notáveis diferenças que apresenta a respeito da ideia de saudade que se desenvolverá a partir do Século d' Oiro Português. ${ }^{13}$ O cerne da definição duartiana pouco se afasta do sentido originário de nostalgia ou solidão causada pelo afastamento daquilo que se ama:

Suydade propriamente he sentydo que o coraçom filha por se achar partydo da presença dalgua pessoa, ou pessoas que muyto per afeiçom ama, ou o espera cedo de seer. E esso medês dos tempos ou lugares em que per deleitaçom muyto folgou. ${ }^{14}$

${ }^{8}$ COELHO, 1978 (2). p. 1002.

${ }^{9}$ COELHO, 1978 (2). p. 1002.

${ }^{10}$ COELHO, 1978 (2). p. 1003.

${ }^{11}$ LOURENÇO, 1999. p. 102-112.

${ }^{12}$ DUARTE, 1942.

${ }^{13}$ Nomeadamente, uma diferença fulcral, posta de manifesto por E. Lourenço: "Mas ficamos perplexos quando (D. Duarte) liga a lembrança saudosa ao prazer, quando, ao comparar o nosso estado presente com o estado passado, em que fomos felizes, achamos o presente melhor". (LOURENÇO, 1999. p. 108).

${ }^{14}$ DUARTE, 1942. p. 95. 
D. Duarte, como o finíssimo psicólogo que ele demonstra ser, faz especial incidência no caráter "emotivo" da saudade, como peculiaridade da alma inteiramente pertencente à esfera da sensualidade ou emotividade, não à racionalidade:

Dygo afeiçom e deleitaçom, por que som sentymentos que ao coraçom perteencem, donde verdadeiramente nace a ssuydade mais que da rrazom nem do siso. ${ }^{15}$

Para além disso, este rei filósofo refere-se à peculiaridade da saudade como um sentimento originado a partir da tensão verificável entre a lembrança e o desejo. Interessa-nos especialmente este ponto do discurso duartiano, pois que ele é também um dos fundamentos da ideia de Saudade em Teixeira de Pascoaes, cuja teoria sobre a Saudade há de nos servir como ponto de referência principal ao pretendermos analisar a visão que da saudade tem um autor como é Drummond de Andrade, no seu livro Sentimento do Mundo. Queremos, pois, manifestar a especial relevância que as seguintes palavras de D. Duarte têm, como antecessoras daquilo que será o cerne da explicação pascoaliana da saudade, como fruto da tensão/união entre a lembrança e o desejo, muito embora tal ideia seja, no rei medieval, intuição apenas esboçada, enquanto no grande poeta do Tâmega se converte numa ideia abundantemente repetida e suficientemente esclarecida, cultivada e delineada até nos seus pormenores. Eis o trecho do Leal Conselheiro onde tal assunto aparece apresentado:

Quando aquela lembrança (dos tempos ou coisas passadas) faz sentir grande desejo, outorgado per toda mayor parte da rrazom, de tornar a tal estado ou converssaçom, com esta suydade vem nojo ou tristeza mais que prazer. ${ }^{16}$

A partir de D. Duarte, a saudade não deixou de ser nunca, à parte de um dos centros da atenção do lirismo e da sensibilidade poética Galaico-Portuguesa que sempre foi, um dos principais pontos de discussão dos filósofos interessados com o estudo da "Alma Lusitana" (com todas

${ }^{15}$ DUARTE, 1942. p. 95.

${ }^{16}$ DUARTE, 1942. p. 96. 
as suas congéneres, Brasileira, Luso-Africana, ${ }^{17}$ Luso-Asiática) e da sua irmã "Alma Galaica", por vezes inspirando obras realmente originais, como a de um Teixeira de Pascoaes ou um Pessoa, escritores estes que hão de tentar fazer diversas aproximações poético-filosóficas para esclarecer o sentido último do conceito de "saudade". Não desejaria estender-me aqui sobre a enorme diversidade de explicações possíveis que sobre a saudade e sua significação têm aparecido ao longo dos tempos, pois correria sem dúvida o risco de resultar imperdoavelmente prolixo e cansativo; vou, portanto, expor duas ou três das mais acertadas definições que recentemente se têm feito sobre o particular, esboçando alguma aportação pessoal sobre o meu ponto de vista a respeito do tema, para depois diretamente comentar a definição e o ponto de vista originais de Carlos Drummond de Andrade, em relação ás teses, tidas como "clássicas" no domínio das teorias sobre a saudade, do escritor Português Teixeira de Pascoaes.

Poderemos, em primeiro lugar, fazer derivar a saudade de uma das mais surpreendentes feições que a alma Portuguesa, segundo Eduardo Lourenço, apresenta aos olhos dos outros povos: essa "mistura fascinante - nas suas verbas - de fanfarronice e humildade, de imprevidência moura e confiança sebastianista, de "inconsciência alegre" e negro presságio, que constitui o fundo do carácter português". ${ }^{18}$ Aliás, e apesar de não acreditarmos no facto de a emigração ser uma das causas originais deste sentimento, sim pensamos, com Eduardo Lourenço ${ }^{19}$ e Joel Serrão, ${ }^{20}$ na importância que no desenvolvimento da experiência saudosa teve a dura realidade da emigração, facto que também liga estreitamente esta à saudade Galega, também fruto das vivências de um povo, historicamente emigrante - tanto ou mais do que o Português - como o Galego. Da mesma maneira, achamos importante, como também o fizeram estes dois

\footnotetext{
${ }^{17}$ Não vamos aqui incidir no particular, pois isso implicaria um inconveniente afastamento respeito ao tema central do nosso artigo, mas não queríamos deixar de mencionar a existência de uma peculiar relação entre a saudade (ou "sodade", no crioulo cabo-verdiano) e um outro sentimento, este exclusivamente cabo-verdiano: a morabeza.

${ }^{18}$ LOURENÇO, 1992. p. 18.

${ }^{19}$ LOURENÇO, 1992. p. 117-126; LOURENÇO, 1999. p. 90.

20 SERRÃO, 1974.
} 
escritores, ${ }^{21}$ a característica significação da saudade como nostalgia dos tempos passados e esplendorosos da época imperial Portuguesa, muito embora tal significação não seja mais do que um dos múltiplos aspectos deste sentimento, o qual, aliás, é anterior, cronologicamente, ao início da expansão marítima.

Dentre as definições dadas pelo ilustre filósofo Eduardo Lourenço, parece-nos especialmente significativa aquela que tenta desenhar em Mitologia da Saudade, onde, depois de estabelecer os limites que separam a saudade doutros estados anímicos como a tristeza, melancolia, angústia, tédio ou nostalgia, ${ }^{22}$ e de discutir as definições de D. Duarte ou D. Francisco Manuel de Melo $^{23}$ e as formas especiais que o portuguesíssimo afeto reveste em Gil Vicente, Bernardim Ribeiro e Camões ${ }^{24}$ ou em Pessoa e Pascoaes ${ }^{25}$ o autor chega à conclusão de que a saudade é um sentimento enigmático e contraditório, um "gosto amargo" ou "delicioso pungir", ${ }^{26}$ e apresenta-nos logo após a sua definição, como sendo a saudade um estado anímico que domina inteiramente a alma, que se apossa dela; um sentimento que não tem um objecto definido, mas que se preocupa extraordinariamente com a passagem do tempo, é dominada pela fluência temporal à qual tenta precisamente vencer, sendo consciente de tal fluência a través da memória, mas a ela se opondo mediante as faculdades de imaginação e fantasia do ser humano. ${ }^{27}$

Para Jacinto do Prado Coelho, ${ }^{28}$ a tese que sobre a saudade se vê refletida na obra de Teixeira de Pascoaes é, fundamentalmente, um paradoxo ontológico, que faz com que a ausência de um ser qualquer faça "mais viva e actuante" a sua presença, facto que per seé já uma contradictio in ajecto, que se pode exprimir sucintamente segundo estoutra afirmação

${ }^{21}$ SERRÃO, 1974. p. 261; LOURENÇO, 1992. p. 19; p. 38; p. 40-41; p. 87;

p. 124-125; LOURENÇO, 1999. p. 89; p. 91.

${ }^{22}$ LOURENÇO, 1999. p. 95-102.

${ }^{23}$ LOURENÇO, 1999. p. 102-112.

${ }^{24}$ LOURENÇO, 1999. p. 109-110.

${ }_{25}$ LOURENÇO, 1999. p. 97.

${ }^{26}$ LOURENÇO, 1999. p. 114.

${ }^{27}$ LOURENÇO, 1999. p. 114-115.

${ }^{28}$ COELHO, 1976. p. 246. 
paradoxal: "quanto mais longe, mais perto". Também segundo este grande crítico literário, ${ }^{29}$ a saudade seria a lembrança de um bem querido, ou bem a imaginação de um bem futuro, ideal ou sonhado, que causa em nós o desejo da sua possessão e a esperança dessa mesma possessão, embora implicando também a amargura perante a impossibilidade de se conseguir tal bem.

Para o poeta simbolista Galego Ramón Cabanillas, a Saudade é, seguindo de perto as teses saudosistas de Pascoaes, "a forza creada, en remanso, do Recordo e a forza creadora e punxante da Espranza, superadas no tempo; o Pasado e o porvir, a Evocación e o Desexo, irmandados nunha fervenza relixiosa". ${ }^{30}$ É para Cabanillas um sentimento de ansiedade daquilo que se não possui, seja por consistir em qualquer coisa de indefinido ou ideal, seja por tratar-se de certo bem perdido. ${ }^{31} \mathrm{O}$ certo é que, para este poeta Galiziano, a Saudade tem um sentido religioso, que ele relaciona diretamente com a mística Céltica, nomeadamente com o tema arturiano do Santo Graal..$^{32}$ Também Teixeira de Pascoaes porá especial ênfase na necessidade de dar vida a uma autêntica religião saudosista. $^{33}$

Será Teixeira de Pascoaes, porém, quem ponha os alicerces básicos da teoria que vê na Saudade o sentimento mais peculiar, identificativo e fundamental da alma Lusitana. O singularíssimo vate Português deixou uma obra inteira, poética e "líricamente filosófica" dedicada à expressão e teorização das suas ideias sobre o tema. A saudade é para ele uma espécie de vendaval lírico e religioso, procedente da imensidade da Natureza, que faz possível a experimentação de uma autêntica paixão

${ }^{29}$ COELHO, 1978 (2). p. 1002.

${ }^{30}$ CABANILLAS, 1981. p. 279.

${ }^{31}$ CABANILLAS, 1981. p. 279.

${ }^{32}$ CABANILLAS, 1981. p. 279.

${ }^{33}$ A ideia é repetida, na obra do visionário Amarantino, com grande assiduidade; baste-nos lembrar esta taxativa afirmação sua, pertencente a O Génio Português: "Quando esta vida psichica se tornar interpretativa das imperfeitas vidas anteriores e com elas se casar, construindo um Universo ideal dentro da realidade do Universo, teremos a verdadeira Religião saudosista" (PASCOAES, 1913. p. 37-38). 
mística, que puxa de nós através de duas forças principais: a Lembrança, que nos impele para o passado, e a Esperança, sublimação do Desejo, faculdade criadora em nós, que faz com que nos decidamos a olhar para o Porvir. $^{34}$

O escritor destas alinhas, como pessoa que tem dedicado um pouco do seu tempo à investigação do sentimento da saudade e os seus reflexos na Literatura e, mais ainda, como herdeiro de recuadas origens familiares Galegas, poderá talvez tentar uma definição pessoal desta curiosa afeição do espírito Galego e Lusófono, lato sensu.

Parece-nos ser a saudade um sentimento de alegria tristonha, ou de tristeza reconfortante. Um estado de depressão sem exageros, de abatimento anímico mas livre de angústia, estado de docilidade e lassitude que propicia uma poderosa doçura e elevação quase mística da alma, que se vê arrebatada por lirismo ascendente, desejoso de eliminar as fronteiras espácio-temporais, num delírio sonhador e fantasioso, amiúde de natureza inconsciente ou semi-inconsciente. O sentimento relevaria, por um lado, de uma impossibilidade de realização de certo desejo, oposta à esperança certa de que tal realização é, de facto, possível, ao menos no nível fantástico e sonhador; por outra banda, derivaria de uma capacidade criativa, nesse mesmo nível, da alma humana, esta se apoiando na lembrança de certos bens, sejam eles passados, entrevistos num futuro que se chega dalguma maneira a enxergar, ou simplesmente distantes no espaço. É dizer, lembrança nostálgica de bens não possuíveis no momento - lembrança que, porém, não inclui o desespero ou a angústia, mas uma tristeza doce e fluida - e esperança, mansa e despreocupada, na possibilidade, escuramente pressentida, de que tal desejo possa ser realizado através de misteriosas realidades mágicas presentes na natureza, que só timidamente podem entrever-se.

\footnotetext{
${ }^{34}$ Esta síntese do pensamento pascoaliano que aqui fazemos, não releva de nenhuma obra sua em particular, sendo antes uma impressão geral originada em nós a partir da leitura do conjunto da sua obra. parece-nos, porém, que a mais exaustiva e alargada exposição da sua "doutrina" sobre a saudade é a que se pode encontrar em Os Poetas Lusiadas (PASCOAES, 1987) e em Arte de ser Português (PASCOAES, 1993).
} 


\section{A saudade na obra Sentimento do mundo de Carlos Drummond de Andrade}

Temos desenhado, até agora, um painel, o mais amplo que nos foi possível no contexto deste artigo, sobre as diferentes teses ou teorias que se têm esboçado sobre a Saudade. Resta-nos, porém, ver a peculiar forma como o sentimento aqui em causa se reflecte numa obra, Sentimento do Mundo, saída da pena de um escritor brasileiro, um dos mais internacionais e conhecidos por todo o mundo, Carlos Drummond de Andrade. Uma obra dentre as muitas que o poeta escreveu ao longo da sua vida, mas que a nós especialmente interessa, pelo facto de ser um poemário centrado numa cosmovisão até certo ponto "saudosa", dominada por um sentimento saudoso do mundo, embora nessa obra, como produto genial de um autor genial, a saudade revista tonalidades específicas e peculiares, que a distinguem bem às vistas da maneira mais estendida como a saudade é observada pelos escritores Lusófonos que tentaram escrever sobre ela. Assim, o primeiro ponto salientável é que a palavra "saudade" não aparece, na obra, escrita sequer uma vez; o sentimento que, porém, denotam muitas das páginas do livro, é justamente a saudade. Mais ainda: o "sentimento do mundo" que alenta no livro, dando nome, aliás, ao livro, é um sentimento intimamente saudoso, embora refletindo umas caraterísticas peculiares, como são a presença de um humor irónico (presente, escusado é dizê-lo, ao longo da obra toda do autor) ou a tonalidade de denúncia, de reivindicação e desgosto perante a situação da sociedade, que ficam bem patentes nestes versos.

O sentimento do mundo é, para Andrade, um sentimento de perda, de esvaecimento do passado nas névoas do tempo, a perda da vida de gente que luta por uma justiça mil vezes negada. Com efieto, o poema inicial, chamado precisamente "Sentimento do Mundo", acaba com estes inequívocos versos:

Quando os corpos passarem,

eu ficarei sozinho

desfiando a recordação

do sineiro, da viúva e do microscopista

que habitavam a barraca

e não foram encontrados

ao amanhecer ${ }^{35}$

35 ANDRADE, 1989. p. 158. 
Amanhecer, porém, que não é tal, pois mais não é do que nova noite: "esse amanhecer/ mais noite que a noite". ${ }^{36}$

Podemos notar, no poema "Confidência do Itabirano", um modo de sentir que revela o prazer e doçura do sofrimento, não porém no sentido pascoaliano de sofrimento gozoso, mas num jeito original de divertimento, um como que "senso lúdico" do sofrer, que o poeta faz derivar da sua qualidade de Itabirano:

E o hábito de sofrer, que tanto me diverte,

é doce herança itabirana. ${ }^{37}$

O poeta sente a inevitável nostalgia por um passado áureo, a qual resulta mais pungente ao ser comparada com a pobreza do presente e o afastamento da sua pátria pequena ideal, Itabira:

Tive ouro, tive gado, tive fazendas.

Hoje sou funcionário público,

Itabira é apenas uma fotografia na parede.

Mas como dói i ${ }^{38}$

Tudo isto é normal dentro da cosmovisão saudosa, e se corresponde à perfeição com as caraterísticas, por todos conhecidas, que a definem. O mesmo acontece com a saudade que no poeta provoca a perda do mundo ideal dos tempos antigos, pormenor este, que já nos aproxima um pouco mais da obra de Teixeira de Pascoaes. A diferença maior está em que o mundo antigo com que se sonha é, diverso: Em Drummond de Andrade, um passado conhecido, não excessivamente distante no tempo, não uma grandiosidade luminosa, mas a doce quotidianidade familiar a todo o mundo, quando vivemos na segurança e confiança que nos dão a paz e a tranquilidade, dados sempre supostos mas que, às vezes, parecem converter-se em ideais longínquos e inatingíveis; poema "Lembrança do Mundo Antigo":

Clara passeava no jardim com as crianças.

O céu era verde sobre o gramado,

A água era dourada sob as pontes [...]

\footnotetext{
${ }^{36}$ ANDRADE, 1989. p. 158.

${ }^{37}$ ANDRADE, 1989. p. 159.

${ }^{38}$ ANDRADE, 1989. p. 159.
} 
o guarda-civil sorria, passavam bicicletas, [...]

As crianças olhavam para o céu: não era proibido [...].

Havia jardins, havia manhãs naquele tempo!!!39

Nada a ver com a ideia do mundo antigo que Pascoaes evocara, por exemplo, em Jesus e Pã, ideia grandiosa, mítica, de radiante luminosidade e aspeto edénico, como amostra que é dos tempos dourados das origens. Eis só um pequeno trecho da pintura nostálgica daquelas épocas evocadas pelo vate:

As ninfas nunca mais os bosques povoaram.

E nunca mais tangeste tua lira, Orfeu!

Os teus deuses, Homero, o Olimpo abandonaram,

Tua Vénus, Lucrécio, há muito que morreu [...]

Quem sabe adivinhar, pitonisa d'Endor?

Quem sabe adivinhar, feiticeiros do Egipto,

Em silêncio, a chorar, voltados prò sol-pôr? ${ }^{40}$

O sentido, porém, é semelhante: a nostalgia amarga de um tempo que se foi, de uma época doirada, tranquila e ansiada nos momentos presentes, como qualquer coisa que se perdeu, dificilmente recuperável, mas que é possível evocar a qualquer momento graças ao poder mágico da lembrança.

O tempo em que Drummond de Andrade escreve é difícil, perigoso, cheio de incertezas, de morte, de guerra, de fome. "Elegia 1938":

Caminhas entre mortos e com eles conversas

sobre coisas do tempo futuro e negócios do espírito. ${ }^{41}$

O afastamento de Itabira, a descoberta da cidade, a sua militância esquerdista e o seu emprego nos jornais revelam decerto ao poeta itabirano um mundo sórdido, cruel, que se exprime na sua poesia como guerra, incerteza, perigo, morte, catástrofe: frente a isso, porém, o poeta escapa, foge idealmente par ao passado da sua Itabira sonhada e lembrada. Mas não quer fugir, não deseja deixar o mundo em que se sente submerso, mas antes denuncia as injustiças que ele e o resto da gente padecem, daí o tom

\footnotetext{
39 ANDRADE, 1989. p. 193.

${ }^{40}$ PASCOAES, 1996. p. 190.

${ }^{41}$ ANDRADE, 1989. p. 194.
} 
evidentemente "social" que reveste tantos dos poemas de Sentimento do Mundo.

A noite e o medo, temas fulcrais da poesia pascoaliana, aparecem em "A Noite dissolve os Homens" como realidade estarrecedora, a tingir de incerteza a vida. Medo real e noite triste, tão diferentes dos medos fantasmáticos e das noites de sonhos loucos do escritor Português. "A Noite dissolve os Homens":

A noite desceu. Nas casas, nas ruas onde se combate, nos campos desfalecidos, a noite espalhou o medo e a total incompreensão. ${ }^{42}$

Bem longe, em verdade, da noite sensual e sonhadora, tão amada pelo Amarantino, como se pode ver neste seu poema de As Sombras, intitulado, precisamente, "De Noite":

Olha a chuva miudinha como cai,

Lá fora, num sussurro que entristece.

É tarde já; meus olhos, descansai...

Que bem, nas noites frias, se adormece! ${ }^{43}$

O mais característico, porém, do pensamento de Teixeira de Pascoaes é a existência, na sua percepção da saudade, de uma poderosa esperança que se acha indestrinçavelmente unida a este sentimento.

Assim, em Jesus e Pãa, num sentido mais bem transcendental, declara Pascoaes:

A esperança acendeu estrelas piedosas

E de lírios vestiu planícies arenosas... ${ }^{44}$

Esperança que aparece unida à ideia de amanhecer, como no fim do poema "De Noite", de As Sombras:

\footnotetext{
42 ANDRADE, 1989. p. 189.

${ }^{4}$ PASCOAES, 1996. p. 84.

${ }^{44}$ PASCOAES, 1996. p. 179.
} 
Ó primeira canção, no Azul sem fim!

Primeiro sol, nas frestas, hesitante;

Mão que meus olhos vens fechar, enfim! ${ }^{45}$

Esperança, enfim, que não deixa de aparecer reflectida nos poemas de Andrade, como uma promessa de justiça, de paz, de segurança, situada num fuuro, desejado e intuído como próximo, que se vai vendo aos poucos chegar. Em "A Noite dissolve os Homens":

Havemos de amanhecer. O mundo se tinge com as tintas de antemanhã e o sangue que escorre é doce, de tão necessário para colorir tuas faces, aurora. ${ }^{46}$

Duas formas assaz diversas, pois, de enfrontar o mesmo sentimento: a saudade. Duas maneiras distintas, mesmo opostas, a de um homem como Pascoaes, que sente que o seu coração "é tudo" ${ }^{47}$ e outra, a de um homem que, como Drummond de Andrade, acha que o seu coração "é muito pequeno" ${ }^{48} \mathrm{e}$, como tal, incapaz de compreender o mundo. No entanto, o sentimento da saudade, tão proteico, tão cambiante, o mesmo recolhe um como outro universo sentimental, um como outro sentimento do mundo.

\section{Referências Bibliográficas}

ANDRADE, Carlos Drummond de. Sentimento do mundo. Edição na Obra Poética: Mem Martins: Europa-América, v. I, p. 157-198, 1989.

CABANILLAS Enríquez, Ramón. A Saudade nos Poetas Gallegos (Discurso de Ingreso na Real Academia Galega). (Pub. inicialmente em 1920). Edição nas Obras Completas, ed. e notas de X. Alonso Montero: Madrid: Akal, v. III, p. 277-289, 1981.

\footnotetext{
${ }^{45}$ PASCOAES, 1996. p. 84.

${ }^{46}$ ANDRADE, 1989. p. 190.

${ }^{47}$ PASCOAES, 1996. p. 64.

${ }^{48}$ ANDRADE, 1989. p. 195.
} 
COELHO, Jacinto do Prado. Ao contrário de Penélope. Venda Nova: Bertrand, 1976.

Saudade: I - Na Literatura Portuguesa. In: COELHO, Jacinto do Prado (Coord.). Dicionário de Literatura (Literatura Portuguesa, Literatura Galega, Literatura Brasileira, Estilística Literária, Porto: Figueirinhas, v. IV, p. 10021003, 1978 (2).

DUARTE, Dom (Dom Duarte, Rei de Portugal e do Algarve). Leal Conselheiro/ o qual fez Dom Eduarte Rey de Portugal e do Algarve e Senhor de Cepta. Edição crítica e anotada, organizada por Joseph M. Piel. Lisboa: Bertrand, 1942.

HAVARD, Robert G. Paralelos entre los sentimientos gallegos y galeses de la saudade/hiraetb: un espejo céltico de la neurosis rosaliana. In: Actas do Congreso Internacional de Estudios sobre Rosalia de Castro e o seu Tempo. Santiago de Compostela: Universidade de Santiago de Compostela - Consello da Cultura Galega, p. 217-224, 1986.

LOURENÇO, Eduardo. O Labirinto da Saudade. Psicanálise mítica do destino Português. 5. ed. Lisboa: Dom Quixote, 1992.

Portugal como destino seguido de mitologia da saudade. 2. ed. Lisboa: Gradiva, 1999.

PASCOAES, Teixeira de (Joaquim Teixeira de Vasconcelos). O Génio Português. Na sua expressão filosófica, poética e religiosa. Porto: ed. da Associação "Renascença Portuguesa”, 1913.

. Os poetas Lusíadas (publicado em 1919). Edição nas Obras Completas, Lisboa: Assírio \& Alvim, v. V, 1987.

. Arte de ser Português (inicialmente publicado em 1920). Edição nas Obras Completas, Lisboa, Assírio \& Alvim, v. X, 1993.

. As Sombras. À Ventura. Jesus e Pã. Edição nas Obras Completas, Lisboa: Assírio \& Alvim, 1996.

PIÑEIRO, Ramón. Filosofía da Saudade. Vigo: Galaxia, 1984.

SERRÃO, Joel. Emigração e Saudade. In: Estética do Romantismo em Portugal. Lisboa, 1974.49

49 Esta obra foi consultada em fotocópia, fornecida pela professora Luísa Madeira Leal, leitora de Portugês da nossa Universidade, a quem sinceramente desejamos agradecer o seu amável gesto ao nos fornecer o texto. 


\section{Resumo}

O autor faz primeiramente uma introdução exaustiva à problemática da explicação do que é a saudade, e acaba por oferecer uma tentativa pessoal de explicação. Depois, trata de ver as peculiaridades da forma de ver a saudade que aparece na obra Sentimento do Mundo, do Itabirano Carlos Drummond de Andrade, mostrando as divergências que esta apresenta com respeito à obra do grande poeta-filósofo da Saudade, Teixeira de Pascoaes.

\section{Resumen}

El autor nos ofrece, primeramente, una introducción exhaustiva a la problemática explicación de lo que significa la saudade, y acaba ofreciéndonos un intento personal de explicación. Después, trata de ver las peculiaridades de la forma de ver la saudade que aparece en la obra Sentimento do Mundo, del Itabirano Carlos Drummond de Andrade, mostrando las divergencias que ésta presenta respecto a la obra del gran poeta-filósofo de la Saudade, Teixeira de Pascoaes. 